\title{
Adjusted productivity costs of stroke by human capital and friction cost methods: a Northern Finland Birth Cohort 1966 study
}

\author{
Ina Rissanen ${ }^{1,2,3} \cdot$ Leena Ala-Mursula ${ }^{1} \cdot$ liro Nerg $^{4} \cdot$ Marko Korhonen $^{4}$
}

Received: 23 June 2020 / Accepted: 22 January 2021 / Published online: 24 February 2021

(c) The Author(s) 2021

\begin{abstract}
Background Productivity costs result from loss of paid and unpaid work and replacements due to morbidity and mortality. They are usually assessed in health economic evaluations with human capital method (HCM) or friction cost method (FCM). The methodology for estimating lost productivity is an area of considerable debate.

Objective To compare traditional and adjusted HCM and FCM productivity cost estimates among young stroke patients. Methods The Northern Finland Birth Cohort 1966 was followed until the age of 50 to identify all 339 stroke patients whose productivity costs were estimated with traditional, occupation-specific and adjusted HCM and FCM models by using detailed, national register-based data on care, disability, mortality, education, taxation and labour market.

Results Compared to traditional HCM, taking into account occupational class, national unemployment rate, disability-free life expectancy and decline in work ability, the productivity cost estimate decreased by a third, from $€ 255,960$ to $€ 166,050$. When traditional FCM was adjusted for occupational class and national unemployment rate, the estimate more than doubled from $€ 3,040$ to $€ 7,020$. HCM was more sensitive to adjustments for discount rate and wage growth rate than FCM.

Conclusions This study highlights the importance of adjustments of HCM and FCM. Routine register-based data can be used for accurate productivity cost estimates of health shocks.
\end{abstract}

Keywords Productivity costs $\cdot$ Human capital method $\cdot$ Friction cost method $\cdot$ Stroke $\cdot$ Cohort study

\section{Introduction}

Productivity costs are costs resulting from loss of paid and unpaid work and replacement costs due to morbidity and mortality. They are usually assessed in health economic evaluations with either human capital method (HCM) or friction cost method (FCM) [1-3]. Due to their major role in the total costs of illnesses, both overestimation and

Ina Rissanen

i.1.rissanen@umcutrecht.nl

1 Center for Life Course Health Research, University of Oulu, Oulu, Finland

2 Medical Research Center Oulu, Oulu University Hospital and University of Oulu, Oulu, Finland

3 Julius Center for Health Sciences and Primary Care, University Medical Center Utrecht and Utrecht University, Huispost nr. STR 6.131, P.O. Box 85500, 3508 GA Utrecht, The Netherlands

4 Oulu Business School, Department of Economics, University of Oulu, Oulu, Finland underestimation of productivity costs may lead to erroneous decision making [3]. The method for estimating lost productivity is an area of considerable debate [2-5]. Both HCM and FCM have their own purposes, seeking answers to different questions [6].

In $\mathrm{HCM}$, the productivity costs are estimated as the value of lost productivity due to a disease over the expected remaining working life $[1,7]$. HCM has been criticized for overestimating costs as it measures lost potential productivity instead of actual values, leading to unrealistically high estimates. HCM is based on the hidden assumption that, had the illness been avoided, the person would have remained alive, healthy and employed until the retirement age. However, it is common that people have several diseases and disabilities [8]. For example, people in a risk for stroke have increased work absence, risk of premature death, disability and unemployment even without the stroke event [9-12]. Also, HCM has been criticized for ignoring the possibility of employee replacement [13].

The FCM was developed to provide an alternative to HCM by focusing on organizational aspects and replacement 
issues [5, 13]. In FCM, the estimated costs accumulate only during the period an organization requires to restore its original production levels after losing a worker, i.e., a friction period [13]. The FCM usually assumes the friction period to be the average duration of vacancies increased with the expected time that employers need to place a vacancy and to train a replacing worker. Even though FCM was developed to offer a different perspective to productivity cost estimation, it does not overcome all HCM issues and leads to some shortcomings of its own. The major criticism against FCM has been that it does not consider the chain of vacancy filling resulting from already employed persons changing jobs [6].

Both HCM and FCM approaches share some limitations. One major limitation is that they do not take into account differences in wage levels between occupational classes. It has been highlighted in previous literature that the applied monetary values should resemble the value of lost productivity as closely as possible [14]. In both approaches, the conventional use of population mean wage might lead to overestimation of productivity costs if the disease burden were concentrated on lower socioeconomical classes. Previous studies of FCM have encouraged the use of different friction periods according to occupational classes since some occupations are less easy to replace $[5,13,15,16]$. However, the friction period does not only depend on the type of occupation, but also the local employment circumstances [6].

It has been found that productivity cost estimates remarkably vary according to the choice of method in many disabling diseases such as stroke, schizophrenia and back pain [17-19]. The lack of consensus concerning which method to use, and what assumptions to make, is a source of ambiguity in productivity cost estimations. Researchers may end up choosing methods depending on whether the high or low productivity cost estimates suit their purposes better [7]. Altogether, there is a need for better understanding on the question-related feasibility and relevance of the competing methods to estimate productivity costs.

This paper highlights the divergences in both HCM and FCM methods based on their underpinning assumptions by using various adjusted models to compute productivity costs of stroke at young age. Stroke is the fourth most common cause of death in the European Union (EU) and even more significant cause of disability, leaving permanent disability to half of the survivors and causing the highest loss of quality-adjusted life years of all diseases [20-22]. In the EU, stroke hits every year more than 600,000 people, a quarter of whom are at working age [21] and the incidence of stroke among young persons ( $<50$ years) is increasing [23-26]. For these reasons, the economic burden of stroke is high, especially at the societal level. The total costs of stroke were estimated 57 billion euros in the EU in 2017 [27], and they are expected to rise [21]. It has been estimated that productivity costs, i.e., costs due to loss of paid and unpaid work, constitute more than half of total lifetime costs per stroke patient in the EU [20]. The productivity costs due to premature death and early retirement are highest among the working-aged, among which the increasing incidence of strokes has raised urgency to evaluate the consequent productivity costs.

Aim of this study was to compare estimates of productivity costs by using both traditional and adjusted HCM and FCM models among young stroke patients. In this study, we (1) use detailed, accurate register-based data of a large population-based birth cohort, (2) control for occupationspecific costs, macroeconomic conditions, vacancy chains and disability conditions on the estimation of productivity costs, (3) apply state-of-the-art productivity cost analyses based on adjusted productivity cost methods.

\section{Materials and methods}

\section{Setting}

We conducted three different model specifications of both HCM and FCM cost estimates in a Finnish stroke population: base models, occupation-specific models and adjusted models. To estimate productivity costs using these models, we linked personal level data on incident strokes, work absence, mortality and income with population level data as detailed below and in Table 1 . We estimated the productivity costs separately in different stroke subtypes: ischemic strokes (IS), transient ischemic attacks (TIA), haemorrhagic strokes (HS) (including subarachnoid haemorrhages and intracerebral haemorrhages) and unspecified strokes (US). Sensitivity analyses were conducted to demonstrate the robustness of the models. All monetary values are presented in 2018 value, i.e., costs not available for 2018 were inflated to 2018 [28, 29]. We used the consumer price index (CPI) as a converter. All analyses were done in $\mathrm{R}$ version 4.0.3 [30].

\section{Individual level data collection}

The Northern Finland Birth Cohort 1966 (NFBC1966) is a non-selective, prospective, population-based birth cohort followed-up since the mid-pregnancy $[31,32]$. The cohort is based on 12,058 alive-born children whose expected birth date was in 1966, representing 96\% of children born in Finnish Provinces of Lapland and Oulu in 1966.

From the entire cohort, all those who had a stroke before age of 50 years were selected into this study population, consisting of 339 stroke patients ( $2.8 \%$ of original cohort population). By the time of data collection, information on stroke diagnoses and hospitalizations was available only until the end of year 2015, i.e. the 50th year of cohort members' life. Diagnoses and hospitalizations were obtained from national 


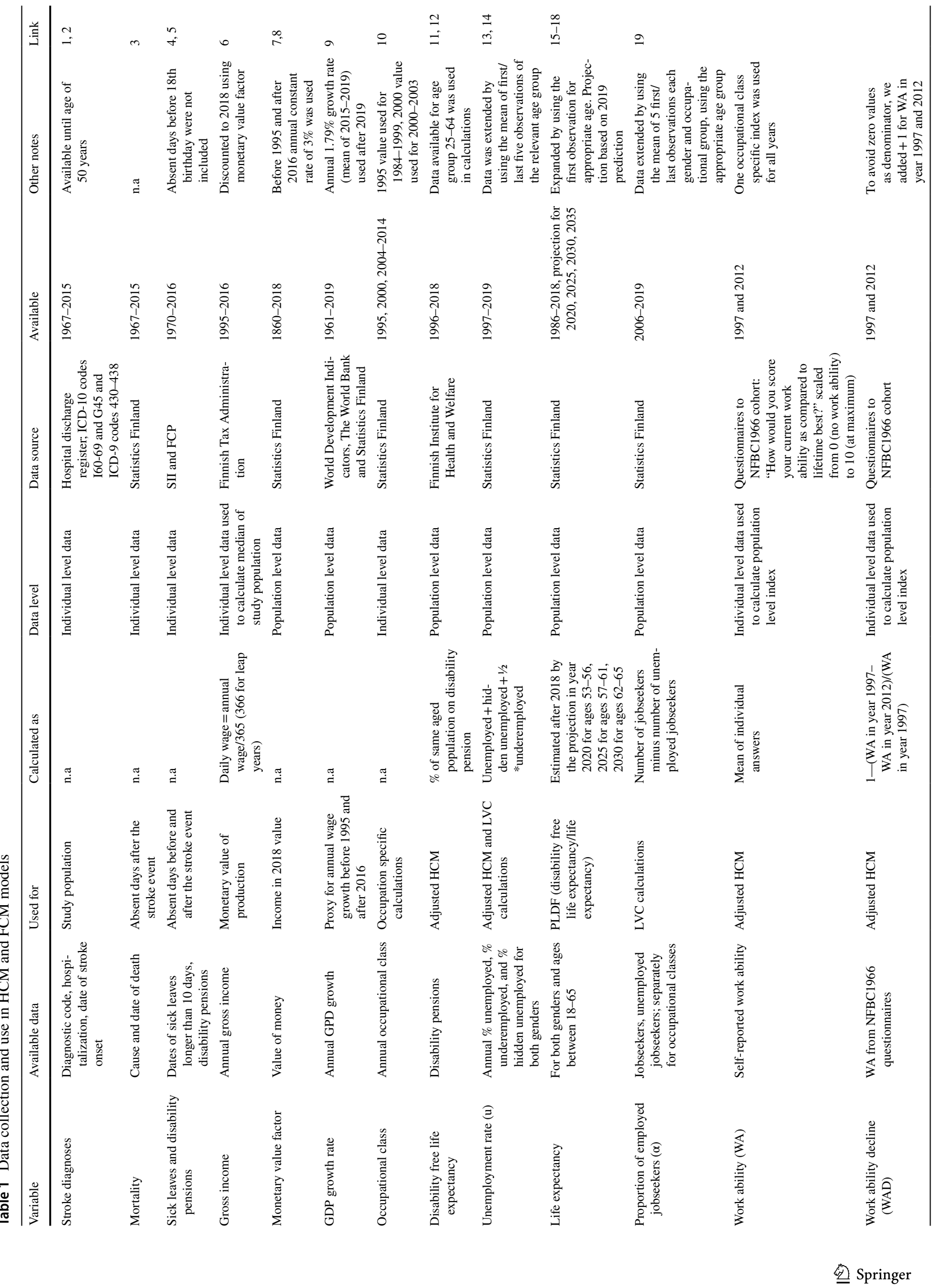




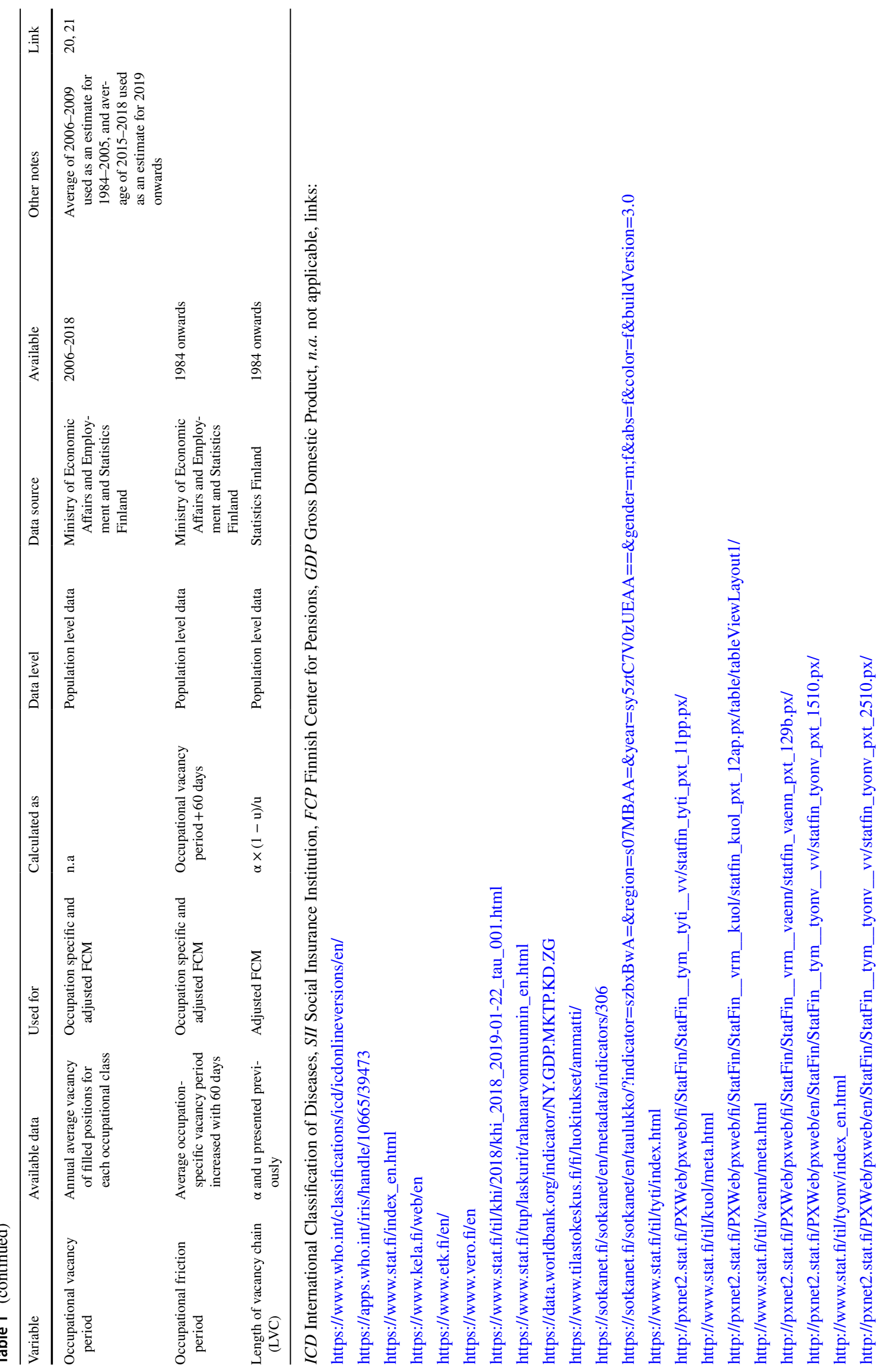


hospital discharge registers, from which the subjects with International Classification of Diseases (ICD) codes I60-69 and G45 from ICD-10 [33], and codes 430-438 from ICD-9 [34] were identified. The individual data included also the date of the stroke onset.

Individual level data of death notes, including cause and date of death, were collected from Statistics Finland [35] until the end of 2015. Data on sick leaves and disability pensions were collected from the registers of Social Insurance Institution (SII) [36] and Finnish Center for Pensions (FCP) [37]. The data of SII included the dates of sick leaves longer than 10 days and non-earnings-based disability pensions between years 1970 and 2016. Earnings-based pensions were collected from FCP until the year 2016. In Finland, pension security covers all paid work, also in self-employment. Sick leaves with length of 10 days or less are not present in these registers because that period is not included in the sickness allowance covered by social insurance. The healthcare registers and sickness allowance systems of Finland are described in the Supplement.

The length of work absence before and after the stroke event was calculated for each stroke patient based on starting and ending dates of sickness leaves, fixed-term disability pensions, permanent disability pensions, death dates and the stroke dates. The data on sick leaves, disability pensions and deaths were used to assign the absence from work from 18th birthday until the end of 2016. Even if the stroke occurred before 18th birthday, absent days before that were not included in productivity cost estimations because productivity costs were assumed to cumulate only when patients were in their working age (18-65 years). If person had died or had been granted a permanent disability pension by the end of 2016, the person was assumed to be absent from work until their retirement age (65 years). The sickness periods shorter than 10 days, which are not covered by the registers, were corrected in the FCM by adding 10 absent days or the number of days between stroke diagnosis and the start of sick leave, to the number of absent days from work. This correction was not included in HCM.

The register of The Finnish Tax Administration [38] was used to obtain individual level data on the gross income of cohort members. The annual gross income data were available from 1995 to 2016. Daily wage was calculated from personal annual gross income by dividing it by 365 (366 for leap years). Median daily wage of the NFBC1966 cohort population available from 1995 to 2016 was used in calculations. The value of past and future daily productivity was discounted at a constant annual rate of $3.0 \%$ recommended in Finnish guidelines [39] to the reference year 2018. We used the CPI as a converter. We used the annual Gross Domestic Product growth rates as a proxy for wage growth before 1995 and for period 2017-2019. An annual growth rate of $1.79 \%$ was used to predict annual wages after 2019 , based on the Finnish annual economic growth rate between 2015 and 2019.

Information on perceived work ability (WA) was obtained during examinations of NFBC1966 members in 1997 ( $n=8767)$ and $2012(n=6774)$, with a survey question "How would you score your current work ability as compared to lifetime best?" scaled from 0 (no work ability) to 10 (at maximum). Instead of using individual values in cost estimates, we calculated an index of overall work ability decline (WAD) in study population.

\section{Population level data collection}

The population level annual data on average disability free life expectancy were obtained from the Finnish Institute for Health and Welfare open access materials [40]. The disability free life expectancy was estimated as the $\%$ of total population of same age receiving disability pension and the annual data were available from 1996 to 2018 . The population level data for the unemployment rate and for life expectancy were obtained from Statistics Finland open access materials [41-43]. The annual unemployment rates were available from 1997 to 2019 and the annual life expectancy data from 1986 to 2018 including projections for life expectancy from 2020 onward.

The annual population level data on vacancy periods according to occupational classes were obtained from official statistics of Ministry of Economic Affairs and Employment between 2006 and 2018 [44]. Information on proportion of employed jobseekers was estimated from the open-source material provided by Statistics Finland [45], defined as number of jobseekers minus number of unemployed jobseekers divided by total number of jobseekers. The annual population level data are available from 2006 to 2019.

\section{HCM}

In HCM, the productivity costs were calculated as days absent from work after a stroke because of sick leave, disability pension or death until the statutory retirement age, multiplied with the value of daily production each year. We used three different approximations for the value.

In the base HCM, the median wage of total NFBC 1966 population, stratified by gender, was used to monetarize the value of production, regardless of differences in actual personal wages. In the occupation-specific HCM, the median wage of each occupational class was used, again stratified by sex. In the adjusted HCM, we further adjusted occupation-specific values for the future labour force participation rates by taking into account proportion of disability-free life expectancy (PLDF) and unemployment coefficients and overall coefficient of work ability decline. These adjustments 
were based on the study of Targoutzidis [6]. More specifically, we estimated the productivity costs (PC) as

$\mathrm{PC}=$ wage $\times t \times \mathrm{PLDF} \times(1-u) \times \mathrm{WAD}$,

where $t$ is the time of absence (until the retirement age), $\mathrm{PLDF}=$ disability-free life expectancy/life expectancy, $u$ is the national annual unemployment rate and $W A D$ is an estimate for overall coefficient of work ability decline.

\section{FCM}

In FCM, the productivity costs were evaluated as length of the absence from work after a stroke multiplied with the value of daily production if absence was shorter than estimated friction period. However, if the length of one's absence from work was longer than the friction period, the friction period was used in calculation instead of length of actual absence. We formed three separate models to estimate the productivity costs.

In the base FCM model, the length of friction period was assumed to be 60 days, the time employers need to place a vacancy and to train replacement of absent worker, based on previous international literature $[15,46]$. In this model the vacancy was assumed to be filled immediately after it was placed. The median wage of the total NFBC1966 population was used to monetarize the value of production in the base FCM model. In the occupation-specific FCM model, separate median wages and friction periods were used for occupational classes instead of the population median. The friction period was annually estimated to be the occupation-specific average vacancy period increased with 60 days that was assumed to be the time employers need to place a vacancy and to train replacement of absent worker.

In the adjusted FCM model, we took into account the length of vacancy chain (LVC) as suggested by Targoutzidis [6]. We did this further adjustment to the occupation-specific FCM model. A simple estimate for the length of the vacancy chain (LVC) is

$\mathrm{LVC}=\alpha \times(1-u) / u$,

where $u$ is the annual unemployment rate and $\alpha$ is the proportion of employed jobseekers.

\section{Sensitivity analyses}

We conducted various sensitivity analyses for our results. For all models, we varied wage growth and discount rates. Wage growth rates $0 \%$ and $4 \%$ were applied to establish the sensitivity of estimate to labour productivity. The discount rates were varied from 0 to $5 \%$. We also conducted analyses where we altered the unemployment rate $(u)$ between minimum and maximum observed rates. In addition to these, the friction period was varied from 60 to 180 days in FCM models, based on minimum and maximum friction periods as used in previous literature [15].

\section{Results}

\section{Characteristics of stroke sample}

During the follow-up from birth to age 50 years, 339 subjects $(2.8 \%$ of total cohort) got a stroke. Of all strokes, 113 (33.3\%) were IS, 108 (31.9\%) were TIA, 85 (25.1\%) were HS (59 subarachnoid haemorrhages and 26 intracerebral haemorrhages) and 33 (9.7\%) were US (Table 2). The median age of stroke onset was lowest in HS and highest in TIA.

At the time of stroke event, 89 (26.3\%) subjects were already on a sick leave or disability pension. After the stroke event, 38 (11.2\%) subjects died until end of 2015. During the follow-up, 240 (70.8\%) stroke patients had an absence from work, and 154 (45.4\%) of stroke patients returned to work force. The median amount of absent days after stroke was 259 (interquartile range 6832) days in all strokes being lowest in TIA and highest in HS.

\section{Productivity costs}

The average lifetime productivity costs per one stroke patient estimated with HCM and FCM base models, occupationspecific models and adjusted models, are shown in Table 3. Using the base HCM the productivity costs were $€ 255,960$ per patient. When wage differences in occupational classes were taken into account, the average productivity costs per one stroke patient were $€ 212,890$. With additional adjustments for disability-free years, unemployment and decline in work ability, the average productivity costs per one stroke patient were $€ 170,030$.

The average productivity costs per stroke patient were $€ 3,040$ when using the base FCM. When both the differences in wages and friction periods according to occupational classes were taken into account, the average productivity costs were $€ 3,890$. With additional adjustment for the length of the vacancy chain, the average productivity costs per one stroke patients rose to $€ 7,200$.

Average productivity costs by adjusted HCM and FCM models were highest in HS and lowest in TIA (Table 4). In adjusted HCM model the average productivity costs were higher among men, whereas in adjusted FCM they were higher among women. Concerning the age of stroke onset, the patients under 40 years had higher productivity costs with adjusted HCM than patients over 40 years, but lower costs when estimated with adjusted FCM. The higher 
Table 2 Characteristics of stroke sample

\begin{tabular}{|c|c|c|c|c|c|}
\hline & $\begin{array}{l}\text { Total }(n=339) \\
\mathrm{N}(\%) / \text { Median (IQR) }\end{array}$ & $\begin{array}{l}\text { IS }(n=113) \\
\mathrm{N}(\%) / \text { Median (IQR) }\end{array}$ & $\begin{array}{l}\text { TIA }(n=108) \\
\mathrm{N}(\%) / \text { Median (IQR) }\end{array}$ & $\begin{array}{l}\text { HS }(n=85) \\
\mathrm{N}(\%) / \text { Median (IQR) }\end{array}$ & $\begin{array}{l}\text { US }(n=33) \\
\mathrm{N}(\%) / \text { Median (IQR) }\end{array}$ \\
\hline \multicolumn{6}{|l|}{ Gender } \\
\hline Male & $172(50.7 \%)$ & $61(54.0 \%)$ & $48(44.4 \%)$ & $46(54.1 \%)$ & $17(51.5 \%)$ \\
\hline Female & $167(49.3 \%)$ & $52(46.0 \%)$ & $60(55.6 \%)$ & $39(45.9 \%)$ & $16(48.5 \%)$ \\
\hline \multicolumn{6}{|l|}{ Occupation at the time of stroke } \\
\hline Military personnel & $5(1.5 \%)$ & $3(2.7 \%)$ & $2(1.9 \%)$ & $0(0.0 \%)$ & $0(0.0 \%)$ \\
\hline Managers & $13(3.8 \%)$ & $1(0.9 \%)$ & $6(5.6 \%)$ & $3(3.5 \%)$ & $3(9.1 \%)$ \\
\hline Professionals & $44(13.0 \%)$ & $11(9.7 \%)$ & $20(18.5 \%)$ & $9(10.6 \%)$ & $4(12.1 \%)$ \\
\hline $\begin{array}{l}\text { Technicians and associate } \\
\text { professionals }\end{array}$ & $52(15.3 \%)$ & $17(15.0 \%)$ & $21(19.4 \%)$ & $9(10.6 \%)$ & $5(15.2 \%)$ \\
\hline Clerical support workers & $23(6.8 \%)$ & $7(6.2 \%)$ & $7(6.5 \%)$ & $6(7.1 \%)$ & $3(9.1 \%)$ \\
\hline Service and sales workers & $60(17.7 \%)$ & $21(18.6 \%)$ & $16(14.8 \%)$ & $16(18.8 \%)$ & $7(21.2 \%)$ \\
\hline $\begin{array}{l}\text { Skilled agricultural, forestry } \\
\text { and fishery workers }\end{array}$ & $8(2.4 \%)$ & $5(4.4 \%)$ & $1(0.9 \%)$ & $1(1.2 \%)$ & $1(3.0 \%)$ \\
\hline $\begin{array}{l}\text { Craft and related trades } \\
\text { workers }\end{array}$ & $34(10.0 \%)$ & $13(11.5 \%)$ & $11(10.2 \%)$ & $9(10.6 \%)$ & $1(3.0 \%)$ \\
\hline $\begin{array}{l}\text { Plant and machine opera- } \\
\text { tors, and assemblers }\end{array}$ & $33(9.7 \%)$ & $10(8.8 \%)$ & $11(10.2 \%)$ & $7(8.2 \%)$ & $5(15.2 \%)$ \\
\hline Elementary occupations & $22(6.5 \%)$ & $4(3.5 \%)$ & $6(5.6 \%)$ & $10(11.8 \%)$ & $2(6.1 \%)$ \\
\hline Unknown & $45(13.3 \%)$ & $21(18.6 \%)$ & $7(6.5 \%)$ & $15(17.6 \%)$ & $2(6.1 \%)$ \\
\hline \multicolumn{6}{|l|}{ Education } \\
\hline Primary school or lower & $39(11.5 \%)$ & $16(14.2 \%)$ & $8(7.4 \%)$ & $12(14.1 \%)$ & $3(9.1 \%)$ \\
\hline Upper secondary education & $183(54.0 \%)$ & $62(54.9 \%)$ & $51(47.2 \%)$ & $54(63.5 \%)$ & $16(48.5 \%)$ \\
\hline Tertiary education & $117(34.5 \%)$ & $35(31.0 \%)$ & $49(45.4 \%)$ & $19(22.4 \%)$ & $14(42.4 \%)$ \\
\hline \multicolumn{6}{|l|}{ Work status at the onset of stroke } \\
\hline Working & $129(38.1 \%)$ & $39(34.5 \%)$ & $54(50.0 \%)$ & $23(27.1 \%)$ & $13(39.4 \%)$ \\
\hline Absent due to sickness & $89(26.3 \%)$ & $32(28.3 \%)$ & $25(23.1 \%)$ & $22(25.9 \%)$ & $10(30.3 \%)$ \\
\hline Unemployed & $121(35.7 \%)$ & $42(37.2 \%)$ & $29(29.9 \%)$ & $40(47.1 \%)$ & $10(30.3 \%)$ \\
\hline \multicolumn{6}{|l|}{ Return to work force } \\
\hline No & $185(54.6 \%)$ & $71(62.8 \%)$ & $47(43.5 \%)$ & $53(62.4 \%)$ & $14(42.4 \%)$ \\
\hline Yes & $154(45.4 \%)$ & $42(37.2 \%)$ & $61(56.5 \%)$ & $32(37.6 \%)$ & $19(57.6 \%)$ \\
\hline Mortality & $38(11.2 \%)$ & $12(10.6 \%)$ & $1(0.9 \%)$ & $24(28.2 \%)$ & $1(3.0 \%)$ \\
\hline Median age at stroke onset & 43.7 (IQR 8.6) & 43.1 (IQR 8.3) & 45.6 (IQR 6.2) & 41.7 (IQR 12.3) & 42.1 (IQR 12.5) \\
\hline \multicolumn{6}{|l|}{ Median number of days off } \\
\hline Before stroke & 46 (IQR 379) & 46 (IQR 686) & 70 (IQR 360) & 18 (IQR 91) & 23 (IQR 1166) \\
\hline After stroke & 259 (IQR 6832) & 514 (IQR 7357) & 19 (IQR 587) & 6410 (IQR 8464) & 93 (IQR 5812) \\
\hline
\end{tabular}

$I S$ ischemic stroke, TIA transient ischemic attack, $H S$ hemorrhagic stroke, $U S$ unspecified stroke, IQR interquartile range

Table 3 Estimated productivity losses per person with three different HCM and FCM models in 2018 Euros

\begin{tabular}{lll}
\hline & HCM costs & FCM costs \\
\hline Base model & $€ 255,960$ & $€ 3,040$ \\
Occupation-specific model & $€ 212,890$ & $€ 3,890$ \\
Adjusted model & $€ 170,030$ & $€ 7,200$ \\
\hline
\end{tabular}

$H C M$ human capital method, FCM friction cost method educational level associated with lower productivity costs with adjusted HCM, but higher costs with adjusted FCM.

Results of the sensitivity analyses are presented in Figs. 1 and 2. Variations in discount rates and wage growth rates altered the base HCM estimation between $-14.4 \%$ and $+29.7 \%$. Occupation-specific HCM model altered between $-15.0 \%$ and $+30.9 \%$ and adjusted HCM model between $-15.1 \%$ and $+31.1 \%$. In FCM sensitivity analyses, the base model altered between $-2.0 \%$ 
Table 4 Adjusted HCM and FCM estimates shown according to clinical and sociodemographic characteristics at stroke onset

\begin{tabular}{|c|c|c|}
\hline & HCM costs & FCM costs \\
\hline \multicolumn{3}{|l|}{ Gender } \\
\hline Male $(n=172)$ & $€ 171,440$ & $€ 6,150$ \\
\hline Female $(n=167)$ & $€ 160,500$ & $€ 7,920$ \\
\hline \multicolumn{3}{|l|}{ Age at onset } \\
\hline Under $40(n=108)$ & $€ 203,990$ & $€ 5,150$ \\
\hline Over $40(n=231)$ & $€ 148,310$ & $€ 7,900$ \\
\hline \multicolumn{3}{|l|}{ Education } \\
\hline Primary school $(n=39)$ & $€ 205,470$ & $€ 4,890$ \\
\hline Upper secondary education $(n=183)$ & $€ 163,950$ & $€ 6,570$ \\
\hline Tertiary education $(n=117)$ & $€ 156,190$ & $€ 8,430$ \\
\hline \multicolumn{3}{|l|}{ Occupation } \\
\hline Military personnel $(n=5)$ & $€ 4,500$ & $€ 6,970$ \\
\hline Managers $(n=13)$ & $€ 69,080$ & $€ 14,050$ \\
\hline Professionals $(n=44)$ & $€ 178,230$ & $€ 9,550$ \\
\hline Technicians and associate professionals $(n=52)$ & $€ 171,420$ & $€ 7,240$ \\
\hline Clerical support workers $(n=23)$ & $€ 191,400$ & $€ 9,570$ \\
\hline Service and sales workers $(n=60)$ & $€ 173,770$ & $€ 8,510$ \\
\hline Skilled agricultural, forestry and fishery workers $(n=8)$ & $€ 212,150$ & $€ 4,730$ \\
\hline Craft and related trades workers $(n=34)$ & $€ 161,700$ & $€ 4,580$ \\
\hline Plant and machine operators, and assemblers $(n=33)$ & $€ 181,210$ & $€ 6,540$ \\
\hline Elementary occupations $(n=22)$ & $€ 172,270$ & $€ 5,870$ \\
\hline Unknown $(n=45)$ & $€ 181,530$ & $€ 3,460$ \\
\hline \multicolumn{3}{|l|}{ Work status at the onset of stroke } \\
\hline Working $(n=129)$ & $€ 61,760$ & $€ 6,380$ \\
\hline Absent due to sickness or disability $(n=89)$ & $€ 340,500$ & $€ 10,370$ \\
\hline Unemployed $(n=121)$ & $€ 148,920$ & $€ 5,240$ \\
\hline \multicolumn{3}{|l|}{ Return to work force after stroke } \\
\hline No $(n=185)$ & $€ 222,400$ & $€ 7,360$ \\
\hline Yes $(n=154)$ & $€ 98,360$ & $€ 6,620$ \\
\hline \multicolumn{3}{|l|}{ Stroke type } \\
\hline IS $(n=113)$ & $€ 184,950$ & $€ 7,820$ \\
\hline TIA $(n=108)$ & $€ 81,430$ & $€ 5,110$ \\
\hline HS $(n=85)$ & $€ 253,250$ & $€ 8,420$ \\
\hline US $(n=33)$ & $€ 153,690$ & $€ 6,950$ \\
\hline
\end{tabular}

$H C M$ human capital method, FCM friction cost method, IS ischemic stroke, TIA transient ischemic attack, $H S$ hemorrhagic stroke, $U S$ unspecified stroke and $+1.6 \%$, the occupation specific model between $-1.5 \%$ and $+1.3 \%$ and the adjusted model between $-1.0 \%$ and $+0.6 \%$. In all models, the productivity costs estimates were lowest when discount rate was highest and wage growth rate was lowest and vice versa. Variation in unemployment rate altered the adjusted HCM model between $-2.1 \%$ and $2.4 \%$ and adjusted FCM model between $-0.7 \%$ and $2.5 \%$.

Changing the maximum friction period from 60 to 180 days increased the values of base FCM model by $133.6 \%$, occupation-specific FCM model by $90.2 \%$ and adjusted FCM model by $90.7 \%$ (Fig. 2). Variation in discount rate or in wage growth rate did not cause substantial additional changes on these estimates.

\section{Discussion}

To our knowledge this is the first study to demonstrate in real-life setting how HCM and FCM productivity cost estimates change when several hidden assumptions in these methods as well as macroeconomic trends are taken into 


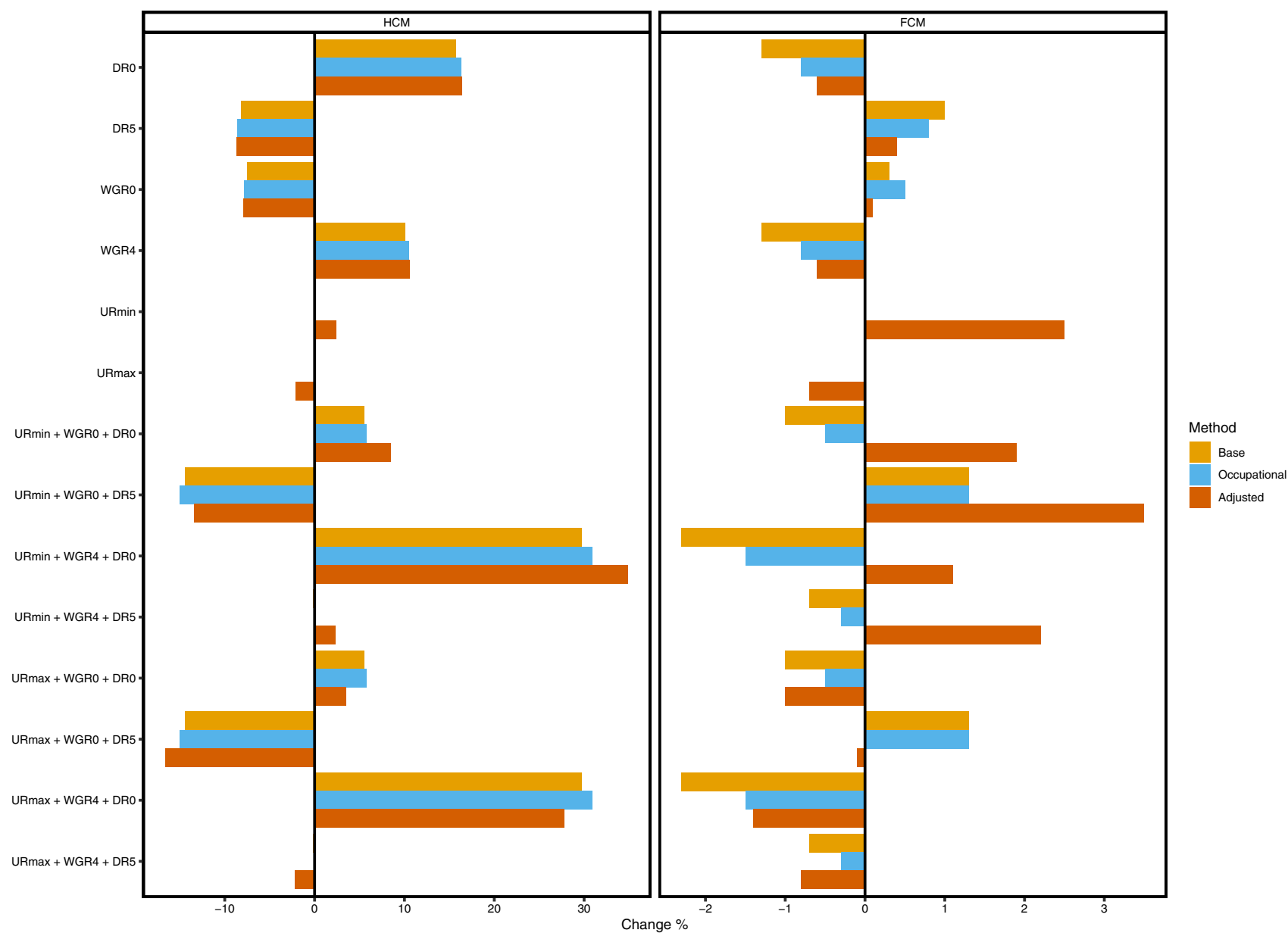

Fig. 1 Results of sensitivity analyses of altering discount rates, wage growth rates, and unemployment rates. $H C M$ human capital method, FCM friction cost method, DRO discount rate 0\%, DR5 discount

account. While we do not provide new methods to estimate productivity costs, our novel study design uses individual level data of a non-selective birth cohort to demonstrate the importance of adjustments when estimating productivity costs.

\section{Comparison of HCM and FCM}

In this study, HCM provided considerably higher productivity cost estimates than FCM. Previously, variation in HCM and FCM estimates has depended on research questions and the studied diseases [7]. Studies assessing short-term sick leaves have found only small differences between the two approaches, whereas studies including productivity costs of mortality and permanent disability have found higher variation $[18,19,47]$. Diseases with low mortality and disability rates or with clear time-restricted courses of disease provide lower differences between HCM and FCM than severe diseases like stroke [7]. A previous study about productivity rate $5 \%, W G R O$ wage growth rate $0 \%, W G R 4$ wage growth rate $4 \%$, URmin minimum unemployment rate, URmax maximal unemployment rate

costs of another cardiovascular disease, coronary heart disease, found that high early retirement rates lead HCM to give more than hundred times higher morbidity cost estimates than FCM [47]. The fact that stroke is a severe condition causing permanent disability or death to many patients explains the high difference between HCM and FCM estimates found here. The choice of friction period plays also a role when comparing HCM and FCM estimates [14]. The longer the friction period, the closer to HCM estimates the results get.

We found that HCM was more sensitive to changes in discount rate and wage growth rate than FCM. In all FCM models, longer maximum friction periods considerably increased productivity cost estimates.

\section{Future participation in labour force}

We adjusted HCM for the hidden assumption that by having had avoided stroke, the person would have remained 


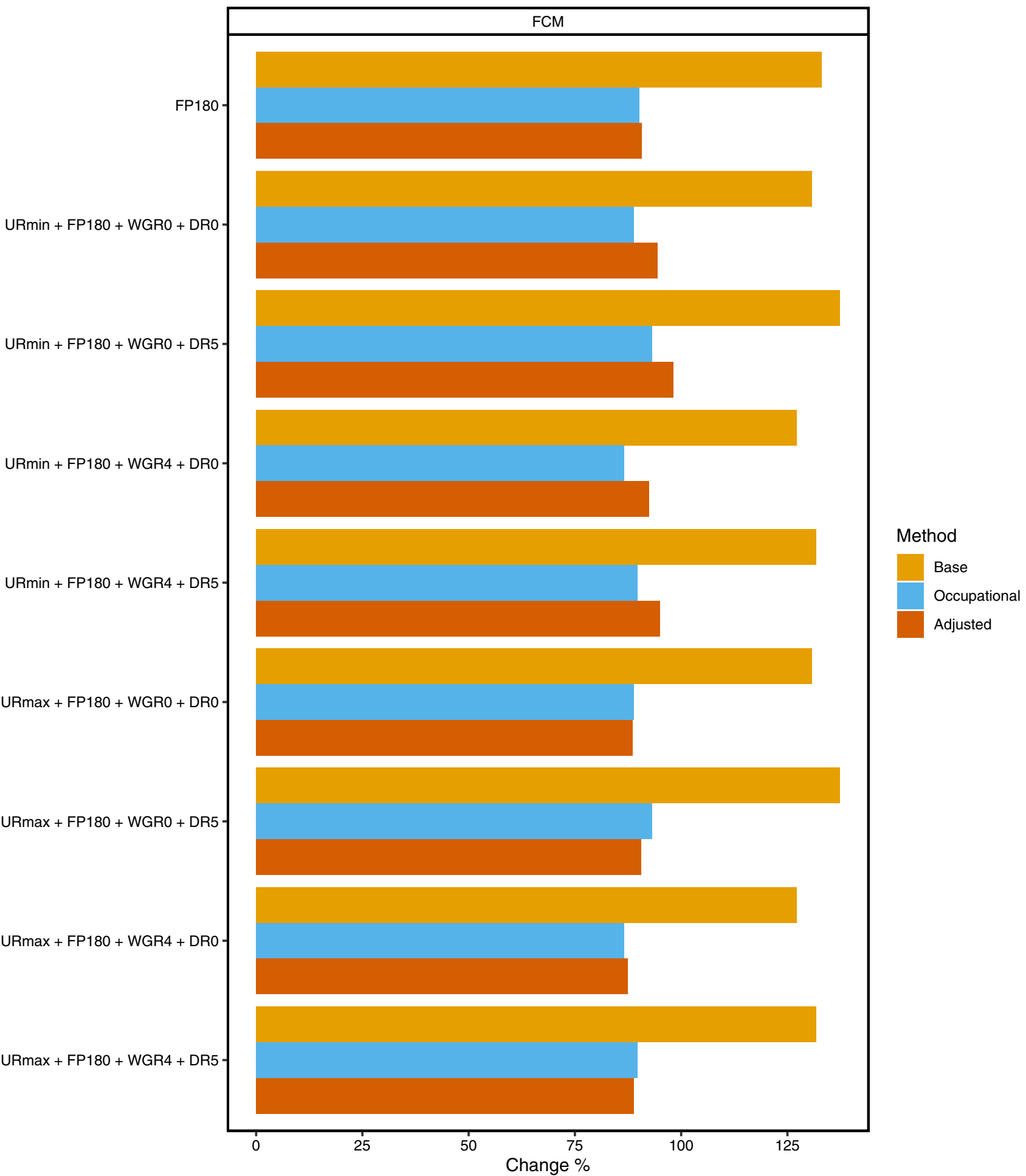

Fig. 2 Results of sensitivity analyses of altering friction periods. $F C M$ friction cost method, FP180 friction period 180 days, DRO discount rate $0 \%, D R 5$ discount rate $5 \%, W G R 0$ wage growth rate $0 \%$,

WGR4 wage growth rate $4 \%$, URmin minimum unemployment rate, URmax maximal unemployment rate

alive, healthy and employed until the retirement age. This was done in adjusted model by taking into account the susceptibility to death and disability due to other conditions

than stroke and the susceptibility to unemployment. We also took into account the wage differences in occupational classes instead of using a median wage of the total 
population, as stroke incidence, mortality and disability are not similar in occupational classes, and as using a population median might overestimate productivity costs. We found that when compared to the traditional way of estimating productivity costs with HCM, by taking into account occupational wage differences, national unemployment rate, proportion of disability free life expectancy, and overall decline in working ability, the estimate decreased by $35 \%$ from $€ 255,960$ to $€ 166,050$.

\section{Vacancy chain and labour market changes}

In this study, FCM was adjusted for the hidden assumption that vacancy created by the disability of a worker will be filled by a previously unemployed person. The adjustment for vacancy chain was done by including the proportion of already employed jobseekers together with national unemployment rate in the adjusted model. We also considered the differences in wages and friction periods between the occupational classes. When the traditional FCM model was adjusted for differences in occupational classes and for the vacancy chain assumption, the estimate increased by $131 \%$ from $€ 3,040$ to $€ 7,020$.

A previous study has showed that labour market changes, in particular unemployment rate changes, have major effects on FCM productivity cost estimates [48]. However, in our sensitivity analyses, variation in unemployment rate did not notably alter the adjusted FCM estimates. Furthermore, our results show that some occupational categories markedly affected recruitment periods and prolonged the time to fill vacancies. This confirms the previous findings that the current practice of using only one pre-determined friction period for labour market circumstances leads to imprecise estimates for productivity costs [15]. It should be noted that we considered a friction period also in short-term absences even though there probably was no vacancy created.

\section{Workplace compensation}

Health economists have paid attention to the existence of compensation mechanisms in workplaces, but it seems that there are contradictory ideas of these [4, 7, 13, 14] [49-52]. Therefore, in this study we decided not to take into account wage multipliers or elasticity of labour time productivity. According to economic theory, the gross wage is an appropriate measure of productivity, because companies continue to employ labour until the marginal cost of labour is equal to the marginal revenue. Our models are based on the assumption that the gross wage is the best estimate of monetary value of production. It should be mentioned that our study population was obtained from a birth cohort eliminating the effect of age on the value of production found in previous studies [53].

\section{Employment and occupation-related socioeconomic status}

Productivity loss estimates due to the disease should capture not only the loss due to the disease itself but also the impact of its co-morbidities and the treatment effects on productivity are concerned. In this study we did not investigate work absence due to stroke, but work absence in stroke population. We found that only $38 \%$ of our study population were working at the time of stroke event. Of our population, $26 \%$ were already absent due to sickness or disability and $36 \%$ were unemployed. Those who were already absent before the stroke event, had higher productivity cost estimates than those who were working at the time of stroke. This highlights that studying costs of one disease is highly difficult, and previous diseases and co-morbidities have huge effect on work ability and productivity cost estimates. Also, previously unemployed had higher HCM estimates than previously working people. This is in line with previous literature showing that previous unemployment is associated with poor prognosis after stroke [54].

Our results showed that the higher the educational level, the higher the adjusted FCM cost estimates. In contrast, adjusted HCM estimates got lower when educational level increased. The same phenomenon was found regarding occupational classes as managers had the lowest HCM estimates and the highest FCM estimates. Previous studies have likewise showed that productivity cost estimates vary by socioeconomic positions [55]. These findings highlight the fact that HCM and FCM measure productivity costs from different perspectives. The results suggest that individuals with higher education and socioeconomic class are more likely to return to work after stroke than individuals with lower education and socioeconomic class. However, since this return to work does not happen inside the friction period, the wage differences override the absence length differences targeted in FCM. It can be postulated that in case of a severe medical disease such as stroke, FCM does not capture the differences in absence lengths between socioeconomic classes even when adjusted for occupation-specific friction periods.

\section{Equity concerns}

Some previous studies have debated over the use of average wage rate of a population for generalizability and equity reasons $[14,56]$. In this study we used gender- and occupational class specific median wages to monetarize the production instead of individual wages. Use of individual wages might encourage inequities in health care 
when labour market discrepancies are transposed to productivity cost estimates and economic evaluations suggest prioritizing health interventions unequally [14, 57]. All productivity cost estimates based on wages might then value the health of high-income earners over that of lowincome earners, of workers over non-workers and of men over women. We showed that using gender-specific median wages, males had on average higher productivity costs in adjusted HCM model, but lower in adjusted FCM model.

In this study, productivity costs of previously nonemployed stroke patients were also estimated to tackle equity concerns. Although there may be a practical justification for excluding productivity losses of non-workers, doing so would probably result in higher valuation of treatment aimed at working people. Such an approach would be hard to justify as equitable. We found that productivity cost estimates, especially HCM estimates, were higher among those previously absent from work due to sickness, disability or unemployment, compared to previously working individuals.

When using the FCM approach, the impact on equity considerations is complex, even if average wage rates were used to value production losses, because the estimates of production loss are partly driven by the duration of the friction period. The friction period will vary by job and by industry but is likely to be shorter for jobs performed by low-paid workers, because such workers tend to be easier to replace. In our study, managers had three times higher FCM productivity cost estimates than, e.g., agricultural or craft workers.

It has been previously suggested that productivity loss should be reported only in physical units, or that only average wages should be used to prevent equity concerns [55]. Our results show that medians of absent days after stroke vary between stroke subtypes more than the productivity cost estimates vary between them. This is in line with previous literature showing that neither HCM nor FCM cost estimates are equivalent to days lost [55]. One explanation to our findings might be reverse causality: patients with earlylife stroke have not had the abilities needed to gain education or high employment status because of their severe disability. Overall, equity considerations should be taken into account in all health care policy making [58].

\section{Value of non-market production and presenteeism}

In this study, the productivity cost estimates were restricted to lost paid employment. No value for nonmarket production, e.g., informal care and unpaid volunteer work, was estimated. This may have caused underestimation of productivity costs. A recent European study found that of total productivity costs during the first year after a stroke, $18 \%$ were due to caregiver time loss [59]. Furthermore, the reduced productivity while at work, presenteeism, was not accounted for. This was inevitable because only objective register data were used in this study and no objective measures are available for presenteeism.

\section{Strengths and limitations}

As the main strength of this study, our data allow us to demonstrate more accurate estimates of productivity costs among young stroke patients compared to previous studies. Importantly, we were able to adjust HCM and FCM models for occupation-specific costs, macroeconomic conditions, vacancy chains and disability conditions. We used longitudinal registered data of real-life stroke patients followed up until the age of 50 years with linkage to nationwide registers of their sickness benefits, mortality and earnings. The objective individual-level data were obtained from a large, unselected, population-based birth cohort, representative of the general Finnish population living in a Northern European welfare society. As a strength of this study design, the productivity cost estimates were compared between different stroke types, occupational and educational classes, and between previously employed and non-employed at the time of stroke.

Importantly, since sickness absence for stroke is usually prescribed for at least two weeks, even in the mildest cases to consider the risk of recurrent attack during that period, the accuracy of the registered data is high. A specific methodological strength indeed stems from the large availability of relevant and reliable Finnish register-based data. Especially, population-level data on occupational-specific vacancy durations and labour market conditions used in this study are unique within international literature. The validity and reliability of Finnish nationwide registers have been proved to be excellent $[60,61]$. Furthermore, there are only few studies that have applied FCM with economic evaluations in countries outside the Netherlands [15].

This study has also limitations. The numbers of cases in stroke subtypes were small and inclusion of a control group was not possible in this analysis. The register data did not include information on the stroke severity or recurrence, symptoms, lesion size, lesion location, or given treatments. Also, the data of SII only included the dates of sick leaves longer than 10 days. Additionally, a previous study in Finland has shown that people not currently working because of unemployment or studying do not receive sickness allowance or disability pension, to which they are similarly entitled to, as easily as employed people [62] If this were the case, the rate of disabled stroke patients could be actually higher than was found, as some disabled stroke patients are not present in registers. However, the productivity cost estimates of previously unemployed 
stroke patients were as high or even higher than of those working at the time of stroke event.

\section{Implications}

This study compared different models estimating productivity costs. Our results can be used for further development of pharmacoeconomic guidelines regarding productivity costs. Whenever data are available, we recommend the use of adjusted models of HCM and FCM as they take into account the criticized hidden assumptions of the models and minimize the effects of possible biases. Adjusted models shown in this study are generic and therefore assumably generalizable to other diseases. However, the results of monetary amounts are disease specific, as seen when comparing the productivity costs in different stroke subtypes. It is known that future capacity to work is associated with stroke severity and clinical recovery after a stroke [16]. Nevertheless, also pre-stroke demographic factors affect the probability to return to work after a stroke [53].

It should be noted that neither the HCM nor FCM model adjustments, i.e., future participation in labour force or vacancy chains, can be measured with one existing value. Future participation in labour force can, however, be estimated based on disability free life expectancy, unemployment rate and decline in work ability. Vacancy chain can be estimated based on unemployment rate and proportion of employed jobseekers. Our results provide empirical support for the adjusted approaches, as suggested in previous studies [62].

A previous study estimating societal costs of strokes in United Kingdom showed that among working aged individuals, total costs were $£ 46,000$ in first year and $£ 26,000$ in subsequent years [63]. Of these, HCM productivity costs accounted for $£ 5,200$ in first year and $£ 5,900$ in subsequent years. It can be assumed that with adjustments presented in our study, the productivity costs of the UK sample would have decreased $35 \%$, and, therefore, the total costs would have decreased $4 \%$ and $8 \%$, respectively. In economic evaluations such a difference in cost estimations due to bias in method assumptions can lead to erroneous decision making.

\section{Conclusion}

This paper compared adjustments for human capital and friction cost methods in evaluating productivity costs of stroke. This study highlights the importance of adjustments, especially related to vacancy durations and macroeconomic conditions, and encourages future studies to make use of routine data to generate more accurate productivity estimates for acute health shocks.
Supplementary Information The online version contains supplementary material available at https://doi.org/10.1007/s10198-021-01271-7.

Author contributions IR planned the study, identified and classified stroke patients from registers, and wrote the first draft of the manuscript. IR and IN calculated durations of sickness absences and pensions of stroke patients from registers. LA-M supervised the work regarding the medical aspects, healthcare registers and sickness allowance systems. LA-M and IN identified and classified occupational classes of patients. IN conducted the statistical analyses and calculated the productivity costs estimates. MK supervised the work regarding the economic aspects and productivity cost estimation methods and created the adjusted models. All authors contributed to writing and editing of the manuscript and approved the final version.

Funding NFBC1966 received financial support from University of Oulu [Grant no. 65354, 24000692]; Oulu University Hospital [Grant no. 2/97, 8/97, 24301140]; Ministry of Health and Social Affairs [Grant no. 23/251/97, 160/97, 190/97]; National Institute for Health and Welfare, Helsinki [Grant no. 54121]; Regional Institute of Occupational Health, Oulu, Finland [Grant no. 50621, 54231]; and ERDF European Regional Development Fund [Grant no. 539/2010 A31592]. This work was supported by Orion Research Foundation. The funders had no role in study design, data collection and analysis, decision to publish, or preparation of the manuscript.

Data availability Data are available from the Northern Finland Birth Cohort (NFBC) for researchers who meet the criteria for accessing confidential data. Please, contact NFBC project center (NFBCprojectcenter@oulu.fi) and visit the cohort website (www.oulu.fi/nfbc or http://urn.fi/urn:nbn:fi:att:bc1e5408-980e-4a62-b899-43bec3755243) for more information.

\section{Compliance with ethical standards}

Conflict of interest The authors declare that they have no conflict of interest.

Open Access This article is licensed under a Creative Commons Attribution 4.0 International License, which permits use, sharing, adaptation, distribution and reproduction in any medium or format, as long as you give appropriate credit to the original author(s) and the source, provide a link to the Creative Commons licence, and indicate if changes were made. The images or other third party material in this article are included in the article's Creative Commons licence, unless indicated otherwise in a credit line to the material. If material is not included in the article's Creative Commons licence and your intended use is not permitted by statutory regulation or exceeds the permitted use, you will need to obtain permission directly from the copyright holder. To view a copy of this licence, visit http://creativecommons.org/licenses/by/4.0/.

\section{References}

1. Drummond, M.F., Sculpher, M.J., Claxton, K., Stoddart, G.L., Torrance, G.W.: Methods for the economic evaluation of health care programmes, 4th edn. Oxford University Press, Oxford (2015)

2. Liljas, B.: How to calculate indirect costs in economic evaluations. PharmacoEcon. 13, 1-7 (1998). https://doi.org/10.2165/00019 053-199813010-00001 
3. van den Hout, W.B.: The value of productivity: human-capital versus friction-cost method. Ann. Rheum. Dis. 69(Suppl 1), 89 (2010). https://doi.org/10.1136/ard.2009.117150

4. Johannesson, M., Karlsson, G.: The friction cost method: a comment. J. Health Econ. 16, 249-259 (1997)

5. Brouwer, W.B., Koopmanschap, M.A.: The friction-cost method: replacement for nothing and leisure for free? PharmacoEcon. 23, 105-111 (2005)

6. Targoutzidis, A.: Some adjustments to the human capital and the friction cost methods. Eur J Health Econ. 19, 1225-1228 (2018). https://doi.org/10.1007/s10198-018-0969-z

7. Pike, J., Grosse, S.D.: Friction cost estimates of productivity costs in cost-of-illness studies in comparison with human capital estimates: a review. Appl. Health. Econ. Health Policy. 16, 765-778 (2018). https://doi.org/10.1007/s40258-018-0416-4

8. Barnett, K., Mercer, S.W., Norbury, M., et al.: Epidemiology of multimorbidity and implications for health care, research, and medical education: a cross-sectional study. Lancet 380, 37-43 (2012). https://doi.org/10.1016/S0140-6736(12)60240-2

9. Sullivan, P.W., Ghushchyan, V., Wyatt, H.R., et al.: Productivity costs associated with cardiometabolic risk factor clusters in the United States. Value Health 10, 443-450 (2007)

10. Owen, A.J., Maulida, S.B., Zomer, E., et al.: Productivity burden of smoking in Australia: a life table modelling study. Tob. Control. 28, 297-304 (2019). https://doi.org/10.1136/tobaccocontrol-2018054263

11. Araujo, M.Y., Sarti, F.M., Fernandes, R.A., et al.: Association between costs related to productivity loss and modified risk factors among users of the brazilian national health system. J. Occup. Environ. Med. 59, 313-319 (2017). https://doi.org/10.1097/ JOM.0000000000000951

12. Lallukka, T., Ervasti, J., Lundström, E., et al.: Trends in diagnosisspecific work disability before and after stroke: a longitudinal population-based study in Sweden. J. Am. Heart Assoc. 7, e006991 (2018). https://doi.org/10.1161/JAHA.117.006991

13. Koopmanschap, M.A., Rutten, F.F., van Ineveld, B.M., et al.: The friction cost method for measuring indirect costs of disease. J. Health. Econ. 14, 171-189 (1995)

14. Krol, M., Brouwer, W.: How to estimate productivity costs in economic evaluations. PharmacoEcon. 32, 335-344 (2014). https ://doi.org/10.1007/s40273-014-0132-3

15. Kigozi, J., Jowett, S., Lewis, M., et al.: Estimating productivity costs using the friction cost approach in practice: a systematic review. Eur. J. Health Econ. 17, 31-44 (2016). https://doi. org/10.1007/s10198-014-0652-y

16. Kigozi, J., Jowett, S., Lewis, M., et al.: Valuing productivity costs using the friction-cost approach: Estimating friction-period estimates by occupational classifications for the UK. Health Econ. 26, 1862-1868 (2017). https://doi.org/10.1002/hec.3513

17. Joo, H., George, M.G., Fang, J., et al.: A literature review of indirect costs associated with stroke. J. Stroke Cerebrovasc. Dis. 23, 1753-1763 (2014). https://doi.org/10.1016/j.jstrokecerebrovasdis .2014 .02 .017

18. Goeree, R., O'Brien, B.J., Blackhouse, G., et al.: The valuation of productivity costs due to premature mortality: a comparison of the human-capital and friction-cost methods for schizophrenia. Can. J. Psychiatry. 44, 455-463 (1999). https://doi.org/10.1177/07067 4379904400505

19. Hutubessy, R.C., van Tulder, M.W., Vondeling, H., et al.: Indirect costs of back pain in the Netherlands: a comparison of the human capital method with the friction cost method. Pain 80, 201-207 (1999)

20. The Burden of stroke in Europe report: overview of stroke burden and care in each EU and SAFE member country. King's College London for the Stroke Alliance for Europe (SAFE) (2017).
21. The Burden of stroke in Europe report: the challenge for policy makers. King's College London for the Stroke Alliance for Europe (SAFE) (2017).

22. Wolfe, C.D., Crichton, S.L., Heuschmann, P.U., et al.: Estimates of outcomes up to ten years after stroke: analysis from the prospective South London Stroke Register. PLoS Med. 8, e1001033 (2011). https://doi.org/10.1371/journal.pmed.1001033

23. George, M.G., Tong, X., Kuklina, E.V., et al.: Trends in stroke hospitalizations and associated risk factors among children and young adults, 1995-2008. Ann. Neurol. 70, 713-721 (2011). https ://doi.org/10.1002/ana.22539

24. Feigin, V.L., Norrving, B., Mensah, G.A.: Global burden of stroke. Circ. Res. 120, 439-448 (2017). https://doi.org/10.1161/ CIRCRESAHA.116.308413

25. Thrift, A.G., Thayabaranathan, T., Howard, G., et al.: Global stroke statistics. Int. J. Stroke. 12, 13-32 (2017). https://doi. org/10.1177/1747493016676285

26. Kissela, B.M., Khoury, J.C., Alwell, K., et al.: Age at stroke: temporal trends in stroke incidence in a large, biracial population. Neurology 79, 1781-1787 (2012). https://doi.org/10.1212/ WNL.0b013e318270401d

27. Luengo-Fernandez, R., Violato, M., Candio, P., et al.: Economic burden of stroke across Europe: a population-based cost analysis. Eur. Stroke J. 5, 17-25 (2020). https://doi.org/10.1177/23969 87319883160

28. Statistics Finland. In: Monetary value factor. https://www.stat.fi/ tup/laskurit/rahanarvonmuunnin_en.html. Accessed November 2020.

29. Statistics Finland. In: Monetary value factor. https://www.stat. fi/til/khi/2018/khi_2018_2019-01-22_tau_001.html. Accessed November 2020.

30. R Foundation for Statistical Computing. R: A language and environment for statistical computing 4.0.3 (2020).

31. Rantakallio, P.: The longitudinal study of the northern Finland birth cohort of 1966. Paediatr. Perinat. Epidemiol. 2, 59-88 (1988)

32. University of Oulu. In: University of Oulu: Northern Finland Birth Cohort 1966. https://www.oulu.fi/nfbc/node/19663. Accessed June 2020.

33. World Health Organization. In: International Classification of Diseases, 10th Revision (ICD-10). https://www.who.int/classifica tions/icd/icdonlineversions/en/ (2019).

34. World Health Organization. In: International Classification of Diseases, 9th Revision (ICD-9). https://apps.who.int/iris/handl e/10665/39473. Acessed Nov 2020

35. Statistics Finland. https://www.stat.fi/index_en.html. Acessed Nov 2020

36. Social Insurance Institution of Finland. https://www.kela.fi/web/ en. Acessed Nov 2020

37. Finnish Centre for Pensions. https://www.etk.fi/en/. Acessed Nov 2020

38. The Finnish Tax Administration. https://www.vero.fi/en. Acessed Nov 2020

39. Pharmaceuticals Pricing Board. New application instructions for health economic evaluation. 2019. https://www.hila.fi/content/ uploads/2020/01/Instructions_TTS_2019.pdf. Accessed March 2020.

40. Finnish institute for health and welfare. In: Population aged 25-64 receiving disability pension, as \% of total population of same age (ind. 306) (2019). https://sotkanet.fi/sotkanet/en/metadata/indic ators/306. Accessed March 2020.

41. Statistics Finland. In: Official Statistics of Finland: Labour force survey [e-publication]. 2020. https://www.stat.fi/til/tyti/index _en.html. Accessed March 2020. 
42. Statistics Finland. In: Official Statistics of Finland: Population projection [e-publication]. 2019. https://www.stat.fi/til/vaenn/ index_en.html. Accessed Mar 2020

43. Statistics Finland. In: Official Statistics of Finland: Deaths [e-publication]. 2019. http://www.stat.fi/til/kuol/2019/kuol_2019_202004-24_tie_001_en.html. Accessed Mar 2020

44. Ministry of Economic affairs and Employment. In: Official Statistics of Finland: Employment Service Statistics [e-publication]. Official Statistics of Finland: Employment Service Statistics. Table: Vacancies by occupation and sector in each province. 2020. https://www.stat.fi/til/tyonv/index_en.html. Accessed Mar 2020

45. Ministry of Economic affairs and Employment. In: Official Statistics of Finland: Employment Service Statistics [e-publication]. Table: Jobseekers by occupation and level of education in each province. 2020. https://www.stat.fi/til/tyonv/index_en.html. Accessed Mar 2020

46. Statistics Finland. In: Employment Service Statistics. http://pxnet 2.stat.fi/PXWeb/pxweb/en/StatFin/StatFin__tym_tyonv__vv/ statfin_tyonv_pxt_2510.px/. Accessed Nov 2020

47. Zheng, H., Ehrlich, F., Amin, J.: Productivity loss resulting from coronary heart disease in Australia. Appl. Health Econ. Health Policy 8, 179-189 (2010). https://doi.org/10.2165/11530520000000000-00000

48. Hanly, P., Koopmanschap, M., Sharp, L.: Valuing productivity costs in a changing macroeconomic environment: the estimation of colorectal cancer productivity costs using the friction cost approach. Eur. J. Health Econ. 17, 553-561 (2016). https://doi. org/10.1007/s10198-015-0698-5

49. Zhang, W., Bansback, N., Anis, A.H.: Measuring and valuing productivity loss due to poor health: A. Crit. Rev. 72, 185-192 (2011). https://doi.org/10.1016/j.socscimed.2010.10.026

50. Strömberg, C., Aboagye, E., Hagberg, J., et al.: Estimating the effect and economic impact of absenteeism, presenteeism, and work environment-related problems on reductions in Productivity from a managerial perspective. Value Health 20, 1058-1064 (2017). https://doi.org/10.1016/j.jval.2017.05.008

51. Nicholson, S., Pauly, M.V., Polsky, D., et al.: Measuring the effects of work loss on productivity with team production. Health Econ. 15, 111-123 (2006). https://doi.org/10.1002/hec.1052

52. Pauly, M.V., Nicholson, S., Xu, J., et al.: A general model of the impact of absenteeism on employers and employees. Health Econ. 11, 221-231 (2002) https://doi.org/10.1002/hec.648

53. Connolly, M.P., Tashjian, C., Kotsopoulos, N., et al.: A comparison of average wages with age-specific wages for assessing indirect productivity losses: analytic simplicity versus analytic precision. Eur. J. Health Econ. 18, 697-701 (2017). https://doi. org/10.1007/s10198-016-0819-9

54. Vågerö, D., Garcy, AM.: Does unemployment cause long-term mortality? Selection and causation after the 1992-96 deep Swedish recession. Eur. J. Public Health 26, 778-783 (2016). https:// doi.org/10.1093/eurpub/ckw053

55. Hanly, P., Maguire, R., Drummond, F., et al.: Variation in the methodological approach to productivity cost valuation: the case of prostate cancer. Eur. J. Health Econ. 20, 1399-1408 (2019). https://doi.org/10.1007/s10198-019-01098-3

56. Lensberg, B.R., Drummond, M.F., Danchenko, N., et al.: Challenges in measuring and valuing productivity costs, and their relevance in mood disorders. Clinicoecon. Outcomes Res. 5, 565-573 (2013). https://doi.org/10.2147/CEOR.S44866

57. Olsen, J.A., Richardson, J.: Production gains from health care: what should be included in cost-effectiveness analyses?. Soc. Sci. Med. 49, 17-26 (1999). https://doi.org/10.1016/S0277 -9536(99)00116-1

58. Krol, M., Brouwer, W., Rutten, F.: Productivity costs in economic evaluations: past, present, future. Pharmacoeconomics. 31, 537549 (2013). https://doi.org/10.1007/s40273-013-0056-3

59. Kotseva, K., Gerlier, L., Sidelnikov, E., et al.: Patient and caregiver productivity loss and indirect costs associated with cardiovascular events in Europe. Eur. J. Prev. Cardiol. 26(11), 1150-1157 (2019). https://doi.org/10.1177/2047487319834770

60. Pajunen, P., Koukkunen, H., Ketonen, M., et al.: The validity of the Finnish hospital discharge register and causes of death register data on coronary heart disease. Eur. J. Cardiovasc. Prev. Rehabil. 12, 132-137 (2005). https://doi.org/10.1097/01.hjr.0000140718 $.09768 . a b$

61. Heliövaara, M., Reunanen, A., Aromaa, A. et al.: Validity of hospital discharge data in a prospective epidemiological study on stroke and myocardial infarction. Acta Med. Scand. 216, 309-315 (1984). https://doi.org/10.1111/j.0954-6820.1984.tb03809

62. Hytti, H.: Why are Swedes sick but Finns unemployed? 15, 131141 (2013). https://doi.org/10.1111/j.1468-2397.2006.00412.x

63. Patel, A., Berdunov, V., Quayyum, Z., et al.: Estimated societal costs of stroke in the UK based on a discrete event simulation. Age Ageing 49, 270-276. https://doi.org/10.1093/ageing/afz162

Publisher's Note Springer Nature remains neutral with regard to jurisdictional claims in published maps and institutional affiliations. 